\title{
Régimen electoral de Madrid a las procuraciones en Cortes: las ordenanzas electorales de los siglos XVI y XVII
}

\author{
juan Manuel Carretero Zamora *
}

1. Cuando en las Cortes de Toledo de 1538 se consagró el definitivo arrasamiento de la representación política estamental (que, por otro lado, había sido más teórica que real) ${ }^{1}$, la representación de los reinos castellanos quedó circunscrita con exclusividad a un limitado número de ciudades y villas que gozaron del privilegio denominado de voto en Cortes. Sin embargo, esta característica específica de la representación castellana (inédita en los Parlamentos y Asambleas Representativas de los

* Universidad Castilla-La Mancha.

- Considero que en Castilla apenas si existió representación política estamental. EI clero y la nobleza (a diferencia de otras asambleas representativas: Cortes de Aragón, Estados Generales de Francia,...) jamás tuvieron representatividad estamental específica en la asamblea castellana. Veánse a este respecto, entre otros, J. VALDEÓN BARUQUE: "Las Cortes medievales castellano-leonesas en la historiografía reciente", estudio preliminar a las Cortes de Castilla de W. Piskorski, Barcelona 1977, pp. XIII-XVII y J. M. Carretero Zamora: "El adelantado Alonso de Lugo, procurador en las Cortes de Castilla de 1510 ", en Anuario de Estudios Atlánticos, 31, 1985, pp. 140-142 y Cortes, monarquía, ciudades. Las Cortes de Castilla a comienzos de la época moderna (1476-1515), Madrid 1988, pp. 417-422.

Sobre las Cortes de Toledo de 1538 y la "expulsión» de los grupos privilegiados los estudios del CONDE DE CEDILLO: Toledo en el siglo XVI después del vencimiento de las Comunidades, discurso de recepción en la Real Academia de la Historia, Madrid 1901, M. Danvila: El poder civil en España, II, Madrid 1885, C. D. HendRICKS: Charles $V$ and the Cortes of Castile: politics in Renaissance Spain, Cornell University, 1976 y, especialmente, J. SANCHEZ MONTES: “Sobre las Cortes de Toledo de 1538-1539. Un procurador del Imperio en un momento dificil», en Carlos V (1500-1558). Homenaje de la Universidad de Granada, Granada 1958, pp. 595-663. 
reinos de la Europa occidental) no implicó que los grupos privilegiados - tanto los de derecho como los de hecho (bien hidalgos, bien caballeros) - quedarán marginados; por el contrario, a través de regímenes electorales dictados por las elites políticas y sociales municipales, y sancionados por la Corona o sus agentes (Consejo de Castilla, corregidores e, incluso, las mismas Cortes), caballeros, hidalgos, nobleza urbana y alta nobleza territorial se aseguraron un cauce propio - que con frecuencia se tornó en exclusivo- de participación política en la asamblea representativa del reino.

Ante la inexistencia de un marco normativo electoral común a las dieciocho ciudades con voto en Cortes, es preciso analizar los regímenes peculiares de cada concejo que, por lo común y como proyección del carácter privativo del derecho electoral castellano bajomedieval y moderno, se articulaban genéricamente en torno a las ordenanzas municipales de elección de oficios, donde la procuración en Cortes alcanzaba casi siempre personalidad normativa específica. En efecto, la legislación general de los reinos castellanos en la edad moderna (Ordenanzas reales de 1484, Nueva y Novísima Recopilación), al garantizar la libertad municipal de elección, concedió plena capacidad normativa a las ciudades para que éstas determinasen a su arbitrio los mecanismos electorales oportunos: "Tenemos por bien que cuando nos embiáremos llamar los dichos procuradores para hacer Cortes, que la elección de los dichos procuradores sea libremente de los concejos, según se contiene en la ley ante desta" ?

Así pues, ante una legislación electoral común inexistente, los patriciados castellanos organizaron unas fórmulas y procedimientos electivos que son básicos para el conocimiento de la propia estructura institucional de las Cortes, los regímenes políticoadministrativos concejiles $y$, sobre todo, la configuración del poder municipal y los mecanismos de reparto social del mismo ${ }^{3}$.

${ }^{2}$ Ordenanzas Reales de Castilla, lib. II, tít. XI, ley II. En análogos términos la Nueva Recopilación, lib. VI, tít. VII, ley VI y Novísima Recopilación, lib. III, tít. VIII, ley II. En la ley I de las Ordenanzas se insistía en la libertad municipal de elección ("y que libremente los puedan elegir en sus concejos"), aunque limitando socialmente el acceso a las procuraciones ("tanto que sean personas honradas y no sean labradores ni sexmeros"). Estas limitaciones electorales originarias son, pues, capitales para la comprensión de los mecanismos electivos castellanos.

${ }^{3}$ Sobre los sistemas de elección y sociología de la representación en las asambleas representativas, véanse entre otros los siguiente trabajos, A. ARRAnz Guzman: "Clero y Cortes castellanas (participación y diferencias estamentales)", en En la España Medieval. Estudios en memoria del prof. D. Salvador de Moxó, II, Madrid 1982, pp. 49-58. T. N. 
2. Dentro del sistema electoral castellano, Madrid quedó adscrito al modelo que podríamos denominar de mitad de oficios ${ }^{4}$. El origen de este peculiar sistema de reparto social del poder político municipal hay que buscarlos en dos razones fundamentales; la primera, en la complicada estructura social y política y en las luchas que por el control de los concejos se desarrolló en las últimas etapas del mundo medieval; la segunda, en la creciente importancia social y económica que fueron adquiriendo ciertos grupos sociales originariamente no incluidos en las elites políticas dirigentes $y$, por tanto, ajenas al control administrativo de los concejos. Así pues, la reserva de ciertos oficios municipales -entre ellos singularmente la procuración en Cortes-constituyó un desahogo de las tensiones políticosociales internas y, sobre todo, propició la necesaria compensación política a ciertos sectores nobiliarios, caballerescos y burgueses que de otra manera no hubieran podido poseer una participación y protagonismo políticos directos. Por este modelo electoral, ciudades como Guadalajara, Madrid, Cuenca y Zamora dieron audiencia y participación representativa directa a ciertos grupos no concejiles en las Cortes castellanas.

Madrid designó, pues, a sus dos representantes en Cortes mediante un sistema electoral mixto que satisfizo los intereses y problemas específicos de dos grupos sociales originariamente independientes: los regi-

BISSON, Assemblies and representation in Languedoc in the thirteenth century, Princeton 1964, J. M. CARRETERo ZamORA: "Oligarquía y representación en Cortes: el proceso electoral en las procuraciones de Toledo y Cuenca (1476-1515), en 1er. Congreso de Historia de Castilla-La Mancha, VII, Toledo 1988, M. Colmeiro: Cortes de los antiguos reinos de León y Castilla. Introducción, I-II, Madrid 1883-1884, R. G. Davies y J. H. DENTON: The English Parliament in the Middle Ages, Filadelfia 1981, F. DUMONT: "La representation de l'ordre du clergé aux Etats français", en Journées Internationales, Paris-Lovaina 1957, pp. 43-49, M. A. R. Graves: The Tudor Parliaments. Crown, Lords and Commons, 1485-1603, Londres 1985, J. M. HAYDEN: France and the Estates General of 1614, Cambridge 1974, D. HiRST: The representative of the people? Voters and voting in England under the early Stuarts, Cambridge 1975, A. D. LUBLINSKAYA: "Les Etats Généraux de 1614-1615 en France", en album Helen Cam, I, 1960, pp. 229-245, F. Martinez Marina: Teoría de las Cortes, Madrid 1979 (reedición), B. PALACIOS MARTiN: “La representación municipal en Cortes. Estudio de la figura del procurador de Zaragoza a mediados del siglo XV", en La Ciudad Hispánica durante los siglos XIII al XVI, Madrid 1987, pp. 1241-1269, J. S. RosSKELL: “The social composition of the commons in a fitteenth century parliament", en Bulletin of the Institute of Historical Research, XXIV, 1951, pp. 152-172, y "The parliamentary representation of Lincolnshire during the reigns of Richard II, Henry IV and Henry V', en Nottingham Medieval Studies, III, 1959, pp. 53-77 y G. O. SAYLES: “Parliamentary representation in 1294, 1295 and 1307", en Bulletin of the Institute Historical Research, III, 1925-1926, pp. 110-115.

${ }^{4}$ Acerca de la reserva de oficios municipales en Castilla, J. I. GutierRrez Nieto: Las Comunidades de Castilla como movimiento antiseñorial, Barcelona 1973, pp. 255-257 y M. C. CARLE: Del consejo medieval castellano-leonés, Bueno Aires 1968, p. 143 y ss. 
dores y los caballeros parroquianos. Sin embargo, hay que advertir que el sistema electoral madrileño de los siglos XVI y XVII no es un modelo petrificado e inmóvil, sino que es la conclusión de una evolución definida y conformada por causas de carácter político y, singularmente, de transformaciones profundas en el seno de los grupos sociales madrileños beligerantes en la política municipal de la villa. A estos factores básicos se une indudablemente otro de no menor importancia: la transformación de Madrid en sede permanente de la corte de los Habsburgo y en lugar favorito de reunión de la asamblea representativa castellana.

En efecto, como en la mayoría de las ciudades con voto en Cortes, Madrid iniciará el proceso de consolidación de su sistema electoral en la época de Juan II, en un contexto social y político caracterizado por la pugna entre la oligarquía y el común por el control de las procuraciones. Esta rivalidad se decantará abiertamente -con la anuencia y apoyo regios ${ }^{5}$ - en favor de las tesis del patriciado que, desde ese momento, ostentará con exclusividad la representación de la ciudad. Desalojado el común, la oligarquía política madrileña inició una nueva rivalidad con el poderoso grupo hidalgo que desde lustros venía pugnando con los regidores en la provisión de los oficios concejiles.

Díaz de Montalvo fue también el que puso los fundamentos jurídicos del régimen electoral madrileño en enero de 1454 (tras numerosos pleitos e instancias) y los mecanismos electivos a las procuraciones en Cortes que pusieron fin a las rivalidades de regidores e hidalgos. La sentencia arbitral de 1454 fue, pues, el fundamento directo de las ordenanzas electorales de los siglos XVI y XVII, y su estudio comparado a lo largo de dos siglos permite, quizá como ningún otro instrumento, analizar las causas

${ }^{5}$ Las secuelas de la pugna social quedan de manifiesto en la legislación de la época en el ya citado párrafo de las Ordenanzas reales de 1484, que reproducen leyes anteriores, donde se adscribe la capacidad representativa sólo a las personas honradas y no a los labradores y sesmeros. Esta prohibición fue fácilmente extrapolable, mediante ordenanzas de,elección de oficios dictadas por la propia oligarquía, al resto de la población no privilegiada.

El fenómeno de exclusión del elemento popular, como he precisado, no es específico de Madrid. En Toledo, por citar un ejemplo significativo, por sentencia del célebre jurisconsulto Alfonso Díaz de Montalvo de 1463 se legalizó la exclusión del común, aunque la práctica -en ese momento legalizada- era muy anterior, quizá de fines del siglo xIV. A este respecto véase mi estudio "Oligarquía y representación...". art. cit. El texto original de la sentencia de Montalvo fue editado por F. Caballero: Conquenses ilustres. Noticias de la vida, cargos y escritos del doctor Alonso Diaz de Montalvo, Madrid 1887, pp. 318-320. 
profundas de la evolución de los procesos electorales ${ }^{6}$. Según dicha sentencia, el procedimiento de elección y los requisitos exigidos a los candidatos eran los siguientes a fines del siglo $\mathrm{XV}$ :

1) El procurador representante de parte del cabildo de regidores era designado mediante un mecanismo muy simple que apenas si evolucionó durante la época de los Austrias. El cabildo de regidores se encontraba estructurado en grupos de cuatro regidores o cuadrilla; cada cuadrilla ocupaba un turno rotatorio mediante el sistema de rueda; establecida la cuadrilla a quien correspondía el turno representativo, el procurador era elegido mediante sorteo de los regidores incluidos excepto aquellos que habian gozado del cargo en turnos anteriores. Es decir, era el clásico sistema castellano de sorteo excluyente. Ahora bien, el mecanismo o recurso del sorteo por insaculación sólo se producía si previamente no se llegaba a unanimidad en votación entre regidores: "Y que la dicha eleçión la hagan los dichos regidores sin afiçión, parçialidad ni vendería... procurando que sea en concordia a persona que lo merezca y sea hábil para servir dicho ofiçio. $Y$ si no se conformasen echen suertes..." ${ }^{7}$.

2) Mayor complejidad y casuistica presentaba la elección y requisitos exigidos al procurador de parte de los caballeros. En primer lugar, al igual que a los regidores, se exigía el difícil vinculo de vecindad en la villa; se era vecino de Madrid por ser natural de ella o haber adquirido tal condición por matrimonio con hija de naturales. No reuniendo estos requisitos, la vecindad era difícil de adquirir (el archivo de Villa atesora una valiosa documentación de cuantos solicitaron la vecindad, no lográndolo en la mayoría de los casos) requiriéndose una permanencia continuada de al menos diez años. Además, se requerian otras condiciones de enorme significación social y económica:

${ }^{6}$ Archivo de Villa (en adelante, A. V.) Secretaría, secc. $1 .{ }^{a}$, leg. 413 , número 15 , Forma que se ha de guardar en las elecciones de oficios que esta villa de Madrid provee en el día del señor San Miguel cada año. Y quando Su Magestad, que Dios guarde, manda llamar a Cortes, en la elección y nominación de sus procuradores en ellas. El texto original de Montalvo fue matizado posteriormente en época de los Reyes Católicos -aunque de manera intrascendente - por el corregidor Juan de Bobadilla. Parece ser que la labor de Bobadilla se limitó a adaptar formalmente la sentencia originaria para su remisión al Consejo de Castilla.

7 Ibidem. El subrayado es mio. 
- Satisfacer parte de los beneficios económicos de la procuración con otros hidalgos: "que el procurador deva dar del aver de la dicha procuración a doze hidalgos de las parroquias a quien les tocare la suerte, cada uno quatro mil ciento sesenta maravedíes".

- Poseer el estatuto de nobleza y "que las informaciones de su nobleza ayan de estar hechas en sus naturalezas, conforme a las leyes y premáticas destos reynos".

- Vinculación personal con una determinada parroquia. A los hidalgos se les pedia tres años de asistencia ininterrumpida en la parroquia por la que optaba a la procuración; el cura párroco debía certificar su pertenencia mediante memoria presentada al escribano de la Villa.

- Imposibilidad de reelección. El candidato proclamado procurador a Cortes no podía volver a optar al cargo hasta que los demás hidalgos de su parroquia lo hubieran ocupado. Aquellos candidatos que, habiendo sido votados por alguno o algunos de sus compañeros, no obtuvieran la aprobación no podían participar en las sucesivas votaciones o en el sorteo.

- Trasmisión del derecho de procuración. En caso que alguna parroquia no tuviera candidato idóneo ("persona hábil y suficiente"), transmitía su derecho a otra de su cuadrilla.

- Pérdida de turno de procuración. Si un candidato proclamado procurador en Cortes no ocupaba el oficio, o bien se encontraba ausente al ser proclamado, se nombraba a otro de su cuadrilla o parroquia, perdiendo el proclamado en primer lugar su turno para próximas convocatorias a Cortes.

- Causas de inhabilitación para el cargo. Eran inhábiles para el cargo representativo los que "ganaren cartas del rey e reyna nuestros señores, ni de ningún grande, ni que aya pedido votos antes deste día, se pueda votar por él, pena de quedar por perjuros y caer en caso de menosvaler"; asimismo, eran inhábiles los cortesanos de los reyes y los que hubieran obtenido de éstos tierras y acostamientos.

- Proximidad a la Villa. Como era frecuente en Castilla, en Madrid se exigía el requisito de residir en las inmediaciones del concejo; según 
la ordenanza de 1454, entraban en la votación y en el sorteo los candidatos que vivian "como dos leguas alrededor".

3. Durante los siglos XVI y XVII la estructura básica del sistema electoral madrileño evolucionó hacia posiciones de reforzamiento y defensa de los intereses sociales y políticos de la oligarquía deseosa de impedir que otros grupos sociales -especialmente los foráneos atraídos por la capitalidad del reino- fracturaran unos privilegios específicos costosamente obtenidos y consolidados. Además -como a continuación veremos-, las ordenanzas municipales de elección de oficios (redactadas por el patriciado a la medida de sus necesidades y aspiraciones políticas) tendieron a endurecer las condiciones originarias en una doble dirección: aumentar las exigencias para la obtención de la vecindad y robustecer las garantías sobre la adscripción al estamento privilegiado. Por otra parte, no casualmente, se observa una "dulcificación" de las condiciones restrictivas hacia los servidores de la monarquía, prueba inequívoca de que gran parte de la oligarquía madrileña más rancia tendió a ocupar puestos en la burocracia central y en la administración territorial de la monarquía católica; con la capitalidad, esta tendencia dulcificadora se hizo quizá más evidente.

Más aún; en mi opinión el verdadero hilo conductor y causa directa de las ordenanzas electorales a Cortes por Madrid en los siglos XVI y XVII es la capitalidad del reino. Hay un argumento suplementario que creo es incuestionable: la primera ordenanza del siglo XVI que altera sustantivamente el sistema electoral es de $1575^{8}$. Antes el régimen establecido con la sentencia de Montalvo y las leves modificaciones de la época de los Reyes Católicos, sólo se ve alterado por resoluciones de la Corona y del Consejo de Castilla ante discusiones y pleitos surgidos por la interpretación de la legislación existente. La primera alteración importante se produce en 1512 por cédula de Fernando el Católico, y es sintomática de esa creciente incorporación del patriciado madrileño a las labores burocráticas de la monarquia: la distancia minima de residencia establecida en dos leguas se extiende a tres ${ }^{9}$, y se rompe la inhabilitación que pesaba sobre los que sirvieran al monarca; el rey católico habilitó como

${ }^{8}$ A.V., Secretaria, secc. 2. ${ }^{a}$, leg. $309, n .{ }^{\circ} 25$, Ordenanzas sobre los procuradores de Cortes hechas por Madrid y aprobadas por el Consejo en 5 de enero de 1535. Esta ordenanza, en realidad, sólo reitera la legislación en ese momento vigente y no aporta novedades normativas significativas.

${ }^{9}$ Ibidem, secc. $2{ }^{\circ}$, leg. $393, n .{ }^{\circ} 35$. 
presentes a los actos electivos a cuantos regidores y caballeros estuvieren a su servicio en su corte, aunque mantuvo la inhabilitación absoluta para los candidatos con oficios en la administración territorial porque "no están en ofiçio que resida en la corte" ${ }^{10}$. De igual manera, las renunciaciones de las procuraciones - sancionadas legalmente con pérdida de turno- se tornaron en frecuentísimas y apoyadas en ocasiones por los corregidores.

¿Cómo era el procedimiento electoral madrileño en el siglo XVı antes de las reformas iniciadas en 1575 ? En el turno de los regidores las trece actas analizadas en el período 1520-1563 nos permiten afirmar que no se produjeron modificaciones sustantivas ${ }^{11}$, predominando las votaciones y acuerdos por unanimidad sobre los recursos al sorteo. Por el contrario, los mayores conflictos y, en consecuencia, matices electorales los ofrece las elecciones en el grupo de los caballeros y escuderos. Quizá el ejemplo de mayor conflictividad lo ofrezca la reunión de $1526^{12}$ : el primer dato que obtenemos es que la elección del procurador caballeresco se efectuaba de forma independiente respecto del procurador elegido por los regidores. En este caso concreto el turno correspondió a la parroquia de San Salvador, y conocemos, además, el procedimiento seguido, los electores e, incluso, las votaciones de cada uno de ellos:

${ }^{10}$ Ibidem, pleito interpuesto por Francisco de Alcalá, regidor de Madrid y corregidor en Palencia.

${ }^{11}$ La serie estudiada tiene la siguiente signatura en el Archivo de Villa, Secretaría:

\begin{tabular}{|c|c|}
\hline AÑO DE ELECCION & FUENTE UTILIZADA \\
\hline 1520 & secc. $2 .^{a}$, leg. $393, n^{\circ} 46$ \\
\hline 1527 & secc. $2 .^{a}$, leg. $393, n^{\circ} 62$ \\
\hline 1527 & secc. $2 .^{a}$, leg. $393, n^{\circ} 64$ \\
\hline 1528 & secc. $2 .^{a}$, leg. 393, n. $^{\circ} 44$ \\
\hline 1528 & secc. $2 .^{a}, \operatorname{leg} .393, n^{\circ} 67$ \\
\hline 1535 & secc. $2^{a}, \operatorname{leg} .393$, n. $^{\circ} 74$ \\
\hline $1532 / 1536$ & secc. $2 .^{a}$, leg. 309, n. $^{\circ} 25$ \\
\hline 1537 & secc. $2 .^{a}, \operatorname{leg} .393, n^{\circ} 77$ \\
\hline 1538 & secc. 2. , leg. $394, n^{\circ} 2$ \\
\hline 1541 & secc. $2 .^{a}$, leg. 394, n. 6 \\
\hline 1542 & secc. $2 .^{a}$, leg. 394, n. $^{\circ} 8$ \\
\hline 1552 & secc. $2 .^{a}$, leg. $394,{ }^{\circ} 20$ \\
\hline 1563 & secc. $2 .^{a}$, leg. 394, n. 22 \\
\hline
\end{tabular}

${ }^{12}$ A.V., Secretaría, secc. 3. ${ }^{\mathrm{a}}$, leg. 457, n. ${ }^{\circ} 13$, reunión de 28 de febrero de 1526. 
Nicolás del Salto

Pedro de Herrera

Francisco de Luzón

Bernardino de Mendoza

Pedro Zapata de Cárdenas

Francisco de Vargas

Pedro Suárez

Pedro Zapata, señor de Barajas

Diego de Herrera
Francisco Fernández de Castilla

Francisco Fernández de Castilla

Juan Zapata ${ }^{13}$

bachiller de la Canal

Juan Zapata

Juan Zapata

Juan Zapata

Juan Zapata

Que se echen suertes

\section{SEGUNDA VOTACION}

Pedro de Herrera

Bernardino de Mendoza

Nicolás del Salto
Que se echen suertes (candidatos: Francisco Fernández de Castilla y bachiller de la Canal).

Que determine el juez de residencia

Que determine el juez de residencia

${ }^{13}$ Juan Zapata era miembro relevante de la oligarquía tradicional madrileña. Su familia estaba situada tanto en el grupo de los regidores como en el de los caballeros; en la votación se le personaliza como «Juan Zapata, sobrino del señor Pedro Zapata, señor de Baraxas". 
Francisco de Vargas

Bernardino de Mendoza

Pedro Zapata

Pedro Zapata de Cárdenas

Pedro Suárez
Que se compruebe la situación personal de Francisco Fernández de Castilla y bachiller de la Canal por si incurren en inhabilitación.

Inhabilitación del bachiller de la Canal $^{14}$

Que entre en las suertes Juan Zapata

Que entre en las suertes Juan $\mathrm{Za}$ pata

Que entre en las suertes Juan Zapata

Esta situación -insisto en que es reiterada entre 1520-1563- solia conducir al sorteo por insaculación una vez que el corregidor o juez de residencia, según el caso, analizaban la ordenanza de 1454 («porque en conformidad no se conçiertan a nonbrar, e conforme a la escriptura e ordenanzas no aviendo eleçión en conformidad se an de echar suertes...").

A partir de 1575 , coincidiendo a mi entender con un replanteamiento del sistema electoral en todas las ciudades con voto en Cortes auspiciado desde la Corona (aunque es una hipótesis que debe confirmarse), los mecanismos electorales madrileños se ven sustancialmente alterados por las ordenanzas de $1575,1579,1594,1616$ y 1632; todas ellas, como he indicado, dirigidas a una finalidad precisa: mantener los privilegios de la oligarquía tradicional y evitar la irrupción en las procuraciones de aquellos grupos sociales atraídos por el establecimiento de la corte.

${ }^{14}$ Se argumento por parte del grupo de los Zapata que el bachiller de la Canal, por ser letrado en pleitos contra los intereses de la villa, "a de ser ynhabilitado de no ser procurador en Cortes". 
El análisis en extenso de estas ordenanzas (véase el resumen manual de 1616 en apéndice 1) conduce ante los siguientes fenómenos:

- Endurecimiento de las condiciones sobre el acceso a la vecindad. Se es natural de Madrid por nacimiento o por ser hijo de natural varón. Desaparece, pues, la posibilidad de acceso directo por matrimonio o por naturaleza del abuelo. Así la ordenanza de 1594 decía textualmente: «... no sean admitidos sino sólamente aquéllos que fueren naturales de esta villa, que ovieren nacido en ella ellos o su padre teniendo casa propia en la parroquia donde la tal suerte cupiere..." ${ }^{15}$. Y la de 1616, aun reconociendo que era vigente para el resto de oficios concejiles, negaba la vecindad por matrimonio (hecho que sí se contemplaba en las ordenanzas de 1454): «ninguno de los dichos instrumentos (se refiere a las ordenanzas) contiene regla de aver de ser admitido el casado con natural desta villa" ${ }^{16}$.

En cuanto al acceso a la vecindad de derecho por permanencia ininterrumpida en la villa, ésta se elevó de diez a veinte años, requiriéndose, además, una antigüedad como vecino de pleno derecho de al menos seis años antes de la elección a procurador a Cortes.

- Control extraordinario de las hidalguías. La primitiva redacción de 1454 ("que las informaciones de su nobleza ayan de estar hechas en sus naturalezas, conforme a las leyes y premáticas de estos reinos») adquiere con la ordenanza de 1575 una rigidez, pormenorización y casuística excepcionales como reacción al creciente número de hidalgos que se asientan en la corte; aunque también, quizá, obedezca a un freno hacia la tendencia ennoblecedora de algunos grupos sociales de dudoso origen ${ }^{17}$.

En efecto, las ordenanzas de 1575 preveían la necesidad -en caso de duda- de presentar padrones donde fehacientemente constaran

${ }^{15}$ A.V. Secretaría, secc. $3{ }^{a}$, leg. $457, n .^{\circ} 2$.

${ }^{16}$ Ibidem, alegación de Juan de Tapia. Este pertenecia a una familia que logró procuración en 1638. Esta alegación confirma el interés de los "nuevos" madrileños del siglo XVII en ingresar en la oligarquía política utilizando el matrimonio como recurso legal.

17 Esta reacción quizá esté relacionada con la petición de las Cortes para que se impida el acceso a las procuraciones a los grupos sociales que «se exerciten en ministerio, trato o grangería... entiendan en obrage de paños y sedas y otras cosas, que es cosa de mucho inconveniente" (Cortes de Madrid, 1576, petición 39, reproduciendo otra de las Cortes de 1571, petición 74). 
como hidalgos el padre y el abuelo del prentendiente ${ }^{18}$. En caso de ausencia de tal instrumento probatorio, las condiciones tendian a endurecerse: cartas ejecutorias, fe de escribano en las naturalezas originarias de la familia, etc. Tal rigor, por el contrario, desaparecía para los hidalgos madrileños cuando "sea (persona) tan notoria y conocida, que no sea necessario hazer semejante prueba».

- Situación privilegiada de la oligarquía en servicio de la Corona. Todos los resabios frente a lo no naturales de la villa tendieron a desaparecer en beneficio de los hijos de la oligarquía madrileña con funciones burocráticas desarrolladas lejos de la corte. La ordenanza de 1575 es en sí misma elocuente, porque tras enumerar un sinfín de prohibiciones señalaba: «... pero aquel que sus padres huvieren sido vezinos originarios, y él o su padre huvieren salido a vivir fuera con algún cargo honoroso, temporal o perpetuo, aunque sea por mucho tiempo, y después ellos o sus hijos lo vuelvan a vivir con su casa poblada, ha de ser admitido como los demás vezinos".

- Reforzamiento del vínculo parroquiano. Por las ordenanzas de 1616 se exigió para ser candidato por una determinada parroquia, tener casa poblada en su jurisdicción, residencia ininterrumpida de tres años al menos y certificación de haber sacramentado durante las tres últimas cuaresmas.

- Prohibición a ciertos oficios de escaso crédito social. Quizá sea una de las aportaciones más significativas de las ordenanzas electorales de la segunda mitad del siglo XVI. Antes de ese periodo las limitaciones sociales, como hemos visto, se limitaron a excluir a los labradores. Ahora —desde 1575- la cerrazón social extenderá dichas limitaciones: “No se ha de admitir ninguno que él o su padre aya usado oficio vil, baxo o mecánico, o esté en servicio de alguna persona". Ese estar en servicio, que podría haber afectado a algunos miembros del patriciado madrileño, fue fácilmente subsanado con el siguiente párrafo final de la ordenanza: "pero no se entiende con los que estuvieren sirviendo a prelados y señores de títulos destos reinos". Con esta reglamentación el exclusivismo fue absoluto en favor de las oligarquias madrileñas.

- Mayoria de edad jurídica. Las ordenanzas nos facilitan en el caso de Madrid un precioso dato que nos era desconocido (salvo en el caso

${ }^{18}$ Apéndice 1, epigrafe VII. 
de Zamora): la mayoría de edad política para funciones representativas era de más de veintidós años.

- Prelación entre los procuradores. Madrid, a diferencia del resto de las ciudades con voto en Cortes, preveía que el procurador del concejo antecedería siempre al procurador de los hidalgos y caballeros.

4. Quizá no encontremos un instrumento más significativo para profundizar en un determinado sistema electoral que los mismos resultados electorales. Ellos, sin interferencias, nos ponen en contacto con una realidad que frecuentemente poco o nada tiene que ver con los procedimientos y normas reglados por ley u ordenanza. En el caso de Madrid el ritmo normativo de sus ordenanzas coinciden plenamente con los resultados electorales en las procuraciones a Cortes. Así pues, en función de los resultados del periodo 1500-1660 (véase apéndice 2), podemos establecer tres períodos con resultados electorales de una cierta coherencia y especificidad:

- 1500-1515, coincidiendo con la segunda etapa del reinado de los Reyes Católicos. Es un período que presenta unas características predibujadas desde finales del reinado de Enrique IV, y caracterizado por la extraordinaria concentración de las procuraciones en pocas familias: Luján, Herrera, Luzón y Zapata.

- 1518-1573. Que comprende todo el reinado de Carlos I y la primera parte del de Felipe II. Este período viene caracterizado por la continuidad y, en algún caso (Herrera, Zapata), por el reforzamiento del exclusivismo en las procuraciones a Cortes. Sin embargo, aunque muy levemente, se empieza a observar el acceso de nuevas familias (Suárez, de la Canal) al hasta entonces restringido grupo de la oligarquia.

- 1579-1660. Es, sin duda, el período más atractivo por la frecuente contradicción entre unas normas electorales que desde 1575 tendieron a cerrar el acceso de nuevos miembros a la oligarquia tradicional, y unos resultados que en modo alguno reflejan dicho desarrollo normativo; en efecto, el análisis tanto de los resultados definitivos como de los mismos procesos electorales, confirman una serie de fenómenos significativos: 
a) Permanecen en las procuraciones algunas familias tradicionales (Zapata, de la Canal), aunque con un protagonismo en clara decadencia.

b) Esta reducida presencia de las familias tradicionales es debida en gran manera al ennoblecimiento de alguna de ellas (Zapata) y a sus excelentes relaciones con la Corona.

c) Se observa la irrupción de familias y personas sin antecedentes en las procuraciones.

d) La gran influencia de la política y de los políticos de la corte, que aprovechan las procuraciones madrileñas para ocupar un espacio político suplementario y controlar desde dentro de las Cortes las posiciones ciudadanas: D. Gaspar de Gúzman, D. Luis Méndez de Haro y Guzmán.

La causa de este último y aparentemente contradictorio fenómeno es, en mi opinión, obvia: con independencia del contenido normativo de las ordenanzas, el poder político central tendió a imponer a sus candidatos obviando las limitaciones legales existentes. A esta razón se unen otras dos de no menor trascendencia: la creciente vinculación entre los regidores, hidalgos y caballeros que en un determinado momento forman un único grupo social indiferenciado; en segundo lugar que, por imposición regia, los regimientos madrileños tendieron en parte a adscribirse a familias vinculadas con el poder central. 


\section{ORDENANZAS PARA LA ELECCIÓN DE PROCURADORES A CORTES POR LA VILLA DE MADRID}

Archivo de Villa, secretaría, sec. $3 .^{a}$, leg. 457, exp. 15.

Forma y orden que se ha de guardar para la elección y nombramiento de el procurador de Cortes cavallero parroquiano de Madrid, y las calidades y requisitos que han de concurrir en los que pretendieren ser admitidos y se admitieren.

I. Luego que se presentare en el ayuntamiento la convocatoria de Su Magestad, se ha de señalar día para la elección y llamar para ella a todos los regidores que estuvieren en Madrid y dos leguas en contorno tres dias antes de la elección '.

II. Llegado el día de ello, han de jurar los regidores que todo amor, parentesco, afición y odio pospuesto, le harán fielmente conforme a las ordenanças, y guardarán secreto ${ }^{2}$.

III. La villa ha de elegir un cavallero principal, honrado, hábil y perteneciente en concordia a la parroquia a quien tocare el turno; y si no se concordaren los cavalleros regidores que a la sazón se hallaren, en tal caso se han de echar suertes entre los cavalleros escuderos de la parroquia, no embargante aya tenido otra procuración o oficios de los que provee la villa ${ }^{3}$.

IV. Ha de ser natural desta dicha villa, nacido en ella él o su padre. $Y$ los que no lo fueren han de aver vivido en ella por lo menos veinte

- Ordenança del año 1575.

2 Ordenança del dicho año de 1575.

${ }^{3}$ Sententia del señor Alonso Díaz de Montalvo, Concordia del señor Juan de Bobadilla y Ordenança del año de 1575. 
años, y de éstos han de estar recibidos por vezinos seis años antes al de la elección ${ }^{4}$.

V. Ha de ser parroquiano de la parroquia donde tocare el turno tres años continuos hasta el día de la elección, y el cura ha de certificar ha sacramentado en ella las tres Quaresmas inmediatas ${ }^{5}$.

VI. No ha de ser recibido por vezino para este efecto ninguno que pretendiere ser nombrado o entrar en suertes, y han de aver passado seís años desde el día que fuere recibido hasta ser admitido. Pero aquél que sus passados huvieren salido a vivir fuera con algún cargo honoroso, temporal o perpetuo, aunque sea por mucho tiempo, y después ellos os sus hijos buelban a vivir con su casa poblada, ha de ser admitido como los demás vezinos, con tal que hayan residido en la parroquia los tres años continuos ${ }^{6}$.

VII. Ha de ser hijodalgo notorio de padre y abuelo conforme a las leyes del reino que sobre esto disponen. $Y$ para que conste el que lo es o no, se entienda que si él, o su padre y abuelo huvieren vivido en esta villa y se ofreciere duda en la possessión que han estado, se cumpla con sacar los padrones della; y si en ellos se hallare que sus antecesores de parte de varón han estado en tal possessión, se esté, y pase por ello sin otra averiguación ni provança. $Y$ no se pudiendo averiguar por los padrones, aya de presentar carta executoria en que esté declarado por tal, o en defecto de no mostrarla, información citada la parte desta villa hecha en el lugar donde su abuelo fuere vezino con fee del escrivano del concejo del tal lugar de la possessión en que estuviere en los padrones; y si no lo presentare, no sea admitido. $Y$ porque el año de mil y quinientos y setenta y cinco no se hazían padrones en Madrid, y podrá ser que el padre y abuelo de algún pretendiente no se halle puesto en ellos, baste provar su possessión y reputación en esta villa, como lo ha de hazer el que su padre o abuelo huviere vivido fuera ella. Esto se entienda quando la tal persona sea tan notoria y conocida que no sea necessario hazer semejante prueba ${ }^{7}$.

\footnotetext{
4 Ordenança del dicho año de 1575 y 1594.

${ }^{5}$ Dichos años de 1575 y 1616.

${ }^{6}$ Ordenança del año de 1575.

7 Ordenança del año de 1575.
} 
VIII. Si de una casa se opusieren a la suerte padre y hijo, no ha de entrar en suertes más de una persona, que ha de ser el padre ${ }^{8}$.

IX. Han de poder entrar en suertes todos los hermanos que huviere en la parroquia no teniendo padre, no obstante estén dentro de una casa no siendo hijos de familia ${ }^{9}$.

$X$. No se ha de admitir ninguno que él o su padre aya usado oficio vil, baxo o mecánico, o esté en servicio de alguna persona. $Y$ si en su contravención fuere admitido, aunque sea por la mayor parte de los regidores, aviendo contradición de qualquiera y expresado causas, la elección y suertes sea ninguna y se aya de bolver a hazer. Pero no se entiende con los que estuvieren sirviendo prelados y señores de título destos reinos, ni los demás que huvieren servido a otras personas, aviendo tres años que los dexaron de servir ${ }^{10}$.

XI. Los cavalleros originarios que tuvieren casas en la parroquia donde tocare el turno han de gozar como estén en los lugares donde tienen hazienda o en servicio de Su Magestad, aunque no ayan vivido los tres años en la casa, con que no ayan de gozar en otra parroquia ${ }^{11}$.

XII. No ha de poder ser admitido ninguno de los que se opusieren que no sea mayor de veinte y dos años ${ }^{12}$.

${ }^{8}$ Ordenança del dicho año de 1575.

${ }^{9}$ Ordenança del año de 1579.

${ }^{10}$ Ordenança del año de 1575.

"Ordenança del año de 1616

12 Ordenança del año de 1575. 
2

RELACIÓN DE LOS PROCURADORES A CORTES POR MADRID EN LOS SIGLOS XVI y XVII

CORTES

PROCURADORES

Sevilla, 1500

D. Juan de Mendoza

Pedro de Córdoba

Toledo, 1502

García Lope de Cárdenas

Alonso de Luján

Toro, 1505

Pedro de Luján

Alonso de Mármol

Valladolid, 1506

Lope Zapata

Fernando de Alcalá

Madrid, 1510

Francisco de Vargas

António de Luzón

Burgos, 1512

Francisco de Herrera

Antonio de Herrera

Burgos, 1515

Francisco de Herrera

Rodrigo de Luján

Valladolid, 1518

Antonio de Luzón

Luís Martínez de Toledo

Santiago-Coruña, 1520

Francisco de Vargas

Francisco de Luján

Valladolid, 1523

Diego de Herrera

D. Juan de Castilla

Toledo, 1525

Juan de Luján

Pedro Zapata de Cárdenas 
Madrid, 1528

Segovia, 1532

Madrid, 1534

Valladolid, 1537

Toledo, 1538

Valladolid, 1542

Valladolid, 1544

Valladolid, 1548

Madrid, 1551

Valladolid, 1555

Valladolid, 1558

Córdoba-Madrid, 1570

Madrid, 1573

Madrid, 1579

\section{Pedro Suárez de Toledo} licenciado del Castillo

Pedro Zapata de Cárdenas licenciado Monzón

Diego de Vargas

Matías del Salto

Juan de Villafuerte

Diego de Herrera

Francisco de Luzón

licenciado Salmerón

Luis de Herrera

Pedro de Herrera

D. Juan Suárez de Estrada

D. Juan Hurtado de Mendoza

D. Bernardino de Mendoza

Pedro Zapata de Cárdenas

D. Pedro de Herrera

D. Jerónimo de Luján

Jerónimo de Pisa licenciado de Herrera

Francisco Fernández de la Canal Álvaro de Luján

Luís de Herrera

D. Francisco de Vargas

Pedro de Medina

D. Íñigo de Cárdenas

Agustín Álvarez de Toledo

Bartolomé Velázquez de la Canal 
Madrid, 1583

Juan Velázquez de la Canal

D. Gabriel Zapata

Madrid, 1586

D. Francisco de Alfaro

Luis Hurtado

Madrid, 1588

D. Juan de Vitoria Bracamonte

D. Ladrón de Guevara

Madrid, 1592

D. Jerónimo de Barrionuevo

Francisco de Monzón

Madrid, 1598

D. Diego de Barrionuevo

Alonso de Muriel Valdivieso

Valladolid, 1602

D. Bernardino de la Torre

D. Gabriel de Galarza

Madrid, 1607

D. Francisco de Rojas y Sandoval

D. Juan de Acuña

Madrid, 1611

Hernán Rodríguez

D. Gaspar Ramírez de Zúñiga

Madrid, 1615

Sebastián Vicente

D. Fernando Vallejo Pantoja

Madrid, 1617

D. Juan Enríquez

Conde de Barajas

Madrid, 1621

D. Antonio Rodríguez Monroy Gaspar de Arnau

Madrid, 1623

D. Pedro de Torres

D. Gaspar de Guzmán, conde de Olivares

Madrid, 1632

Luis Hurtado

Juan de Palma

Madrid, 1638

D. Pedro González

D. Jerónimo de Tapia 
Madrid, 1646

D. Bernardo de Salas

D. Domingo de Mena

Madrid, 1649

D. Juan de Quero

D. Luis Méndez de Haro y Guzmán

Madrid, 1655

D. Fernando de Láriz

D. Juan de Lorenzana

Madrid, 1660

D. José Vicente de Borja

D. Alonso de la Encina 